\title{
Reward Seeking as a Predictor of Drug Use in Youth: Effect of Gender and Social Environment
}

\author{
Gennady G. Knyazev*
}

State Research Institute of Physiology, Siberian Branch of the Russian Academy of Medical Sciences, Timakova Str., 4, Novosibirsk, 630117, Russia

\begin{abstract}
Drug use was investigated in 3476 college and university students. The participants also filled out a set of personality questionnaires along with questions about relationships with peers, parents, and boy/girlfriend. Behavioral Activation was the best personality predictor of drug use. Peer and parent support decreased the strength of association between Behavioral Activation and drug use in females, but not in males. On the other hand, drug use in near social environment significantly increased the strength of association between Behavioral Activation and drug use in males, but not in females. This evidence suggests that in predisposed to drug use youth social environment may act both as a protector and a risk factor. The former influence is stronger in females, the latter - in males.
\end{abstract}

Keywords: Drug use, youth, personality, behavioral activation, social environment.

\section{INTRODUCTION}

Drug use is recognized as one of the most hazardous behaviors in youth. In recent years, various official statistics clearly indicate an increase in drug misuse among youths, and Russia does not make an exception [1]. It is well established that some young people are more vulnerable to becoming involved with drug use than others. A better understanding of their underlying attitudes may help to predict variations in overt behavior. There is a wellestablished tradition of research concerned with the relationship between substance use and Eysenck's personality factors. The wide literature on the relationship between Eysenck's dimensional model of personality and the use of drugs, alcohol and tobacco confirms that Psychoticism (P) is a key personality factor in this area [2].

Another personality construct, whose relation to substance use is broadly explored, is that of sensation seeking. Sensation seeking appears to be a neurochemically based personality trait characterized by a need for stimulation, reflected in individuals likely to engage in risktaking behaviors. Individuals relatively high in sensation seeking may have a biologically based need for stimulation, making them more vulnerable to substance abuse and more susceptible to the reinforcing effects of pleasurable stimuli, including the effects of drugs [3]. An array of studies has demonstrated that individuals high in sensation seeking appear to be drawn to smoking, alcohol use, and use of illicit drugs.

Gray's theory, which appeared as a modification of Eysenck's personality theory [4], and now has come to be known as Reinforcement Sensitivity Theory [5] fits more

*Address correspondence to this author at the State Research Institute of Physiology, Siberian Branch of the Russian Academy of Medical Sciences, Timakova Str., 4, Novosibirsk, 630117, Russia; Tel.: +7-383-3334865; Fax: +7 383 3324254; E-mail: knyazev@physiol.ru closely than Eysenck's theory to the core of craving which is one of the prominent characteristics of substance abuse. Gray has proposed two major neurological systems, the Behavioral Inhibition System (BIS) and the Behavioral Activation System (BAS). The BIS is described as sensitive to signals of punishment and frustrative non-reward, and as promoting avoidance behavior and feelings of anxiety. The BAS is sensitive to signals of reward and relief from punishment and regulates appetitive motivation (desirerelated). These two brain systems are postulated to underlie the personality dimensions of anxiety and impulsivity. As Pickering and Gray [6] indicate "the personality trait label of "Impulsivity", when used in relation to the reactivity of a person's Behavioral Activation System, is really a shorthand for impulsive sensation seeking". Gray [4] argued that the BAS personality dimension was situated in the Extraversion $\mathrm{x}$ Neuroticism plane of Eysenck's personality system with subjects high on this dimension being neurotic extraverts. In subsequent revisions of the Eysenck scales [7] the Impulsivity content is found largely in the Psychoticism scale rather than Extraversion.

Therefore, the Behavioral Activation construct capturing such traits as Psychoticism and sensation seeking seems to be the most promising candidate for a personality trait underlying addictive behavior. Indeed, as Pickering and Gray [6] point out "in a highly BAS reactive subject, the BAS-controlled approach component will tend to predominate, and so these subjects will exhibit a lot of risky, sensation-seeking behaviors". Empirical evidence shows that BAS predicts alcohol craving [8], binge eating [9], and involvement in drugs [10,11].

For substance use epigenetic models suggest that temperament phenotypes will not have a direct relationship with a complex behavior pattern such as substance use, but rather will affect patterns of social relationships that represent more proximal risk factors for substance use, such as affiliation with deviance-prone peers [12]. Scar and 
McCartney [13] suggested that temperament characteristics might exert a systematic influence on the nature and impact of peer relationships. Moffit [14] also suggested that some temperamental dimensions predispose individuals toward more affiliation with, and being affected to a greater extent by, deviant peers. She proposed that such a process might be involved in the interaction between individual characteristics and social contexts. In addition, the epigenetic analysis by Tarter et al. [15] proposed that substance use outcomes depend on an interaction between a temperament phenotype and the social context of development.

On the other hand, it is well known that development of problem behavior occurs through transactions between a child's temperament and the family environment [16]. Family risk factors and relationships with parents [17] are known to be of particular prognostic significance. For young people, social support from older generations, including parents and teachers may be an important protective factor in regard to substance use.

Among known protective factors task orientation is of particular interest [18]. Task orientation has been suggested as relevant for reducing the impact of risk-promoting circumstances [19]. Learning and education is a key life goal in youth. There is a rich literature of links between academic underachievement and psychopathology with most authors recognizing bidirectional relationships between the domains [20]. Therefore, educational aspiration could be considered as a potential protective factor for substance use.

Emmons [21] showed that various features of one's goals (including the existence of important goals, progress towards those goals, and conflict among different goals) can have important implications for emotional and cognitive wellbeing, and the way we approach our goals influences subjective well-being. In context of personality-life outcomes relationship, the study of subjective well-being is particularly interesting because, on the one hand, it is considered as a general measure of people's happiness and, on the other hand, due to its heritability and stability across the life, its link with personality raises no doubts [22]. In relation to substance use, subjective well-being may be considered as a protective factor, whereas subjective illbeing - as a risk factor.

The aim of the present study was to estimate the predictive power of personality factors derived from Eysenck's and Gray's theories and an array of related psychosocial variables for drugs involvement in mainstream Russian youths. We supposed that behavioral activation would be the most potent predictor of problem behavior and that its influence would be moderated by variables measuring characteristics of social environment. Additionally, the effect of gender was examined in all data analyses to reveal possible gender specificity in the obtained relations.

\section{METHOD}

\subsection{Participants and Procedure}

The data were collected in 2003 year as a part of the Novosibirsk Study "Social and psychological aspects of substance abuse among young people: risk and protective factors". The sample included 3650 college and university students (1436 males, 2214 females) aged 16 to 35 years (mean 20.16, S.D. 3.6) attending 31 different educational institutions in the Novosibirsk region during the first half of 2003. Participants gave informed consent to the study and completed anonymously a set of questionnaires. The study was approved by the Institute's ethical committee.

\subsection{Measures}

\subsubsection{BAS and BIS Measures}

The Gray-Wilson Personality Questionnaire (GWPQ) [23] was devised to measure six dimensions basic to Gray's theory of personality. These have been found to cluster into two major factors, identified as BIS and BAS measures respectively [24]. GWPQ scales have been found to be good predictors of adolescents' psychopathology scores [20, 24] and show consistent correlations with psychophysiological measures [25, 26]. A short form (28 items) of the GWPQ has been developed which showed reasonable psychometric properties and correlations with psychopathology measures in adolescents [27]. This was further shortened to 24 items and used in studies of adolescents' substance use $[10,11]$. In this study the BIS and BAS scales demonstrated adequate and relatively low reliabilities, respectively (alphas of 0.74 and 0.61).

\subsubsection{Short inventory for Measuring Eysenck's Personality Factors}

A short Russian version of the Eysenck Personality Questionnaire (EPQ) [11] was used for measuring Extraversion, Neuroticism, and Psychoticism. All but one scales demonstrated adequate reliability (alphas of 0.73 for Extraversion, 0.72 for Neuroticism, and 0.56 for Psychoticism). Psychoticism showed rather low reliability, which is frequently the case, particularly in the study of Russian EPQ properties [28].

\subsubsection{Sensation Seeking and Subjective Well-Being}

Sensation seeking [29] and Subjective Well-being [30] were measured by short scales ( 8 and 4 items, respectively), which in this study showed adequate reliability (alphas of 0.71 and 0.66 , respectively).

\subsubsection{Drug Use}

The development of measures was guided by the previous studies $[2,31]$ and the expertise of the sociologists in the research team who have conducted surveys of the life styles and views of young people in the Novosibirsk region for about 15 years [32]. The response format varied for different items. The introductory questions enquired whether or not the respondent had ever tried drugs ("yes" = 2, "have tried and given up" =1, and "no" =0). The second question asked what was the respondent's age when s/he tried drugs for the first time. Duration of drug use was calculated as the respondent's age minus the age of the first try. The third question asked about the frequency of current use ("do not use" $=0$, "have tried and given up" = 2, "1-2 times a year" = 3 , "less than 1 time a month" $=4$, " $1-2$ times a month" $=5$, "1-2 times a week" $=6$, "1 time a day" $=7$, "several times a day" =8). The fourth question asked whether the respondent ever distributed drugs ("yes" = 2, "cannot say" = 1, and "no" $=0)$. The fifth question asked whether the respondent ever had drug-related conflicts with other people ("yes" = 1, "no" 
$=0$ ). Additional item asked respondents what drugs, if any, they had tried. "Do not use" scored 0, those who indicated marijuana or other hemp derivates scored 1, those who indicated derivates of opium, cocaine, hallucinogenic drugs, or stimulants scored 2, those who indicated that they combined hemp derivates with opium, cocaine, hallucinogenic drugs, or stimulants scored 3, and those who indicated that they combined several hard drugs scored 4. In items 2, 3 , and 6 missing values, if they were combined with a negative answer to the first question, were treated as "do not use". A total score was calculated as the natural logarithm of the four scores' sum plus 1, reliability for a composite measure being 0.77 . Scores ranged from 0 to 3.2, mean (Std. Deviation) $=0.2(0.5)$.

\subsubsection{Social Support}

Social support was measured by the Swickert et al.'s [33] scale comprising four subscales (two items each): Parent's support, Peer's support, Boy/girl-friend's support, and Teacher's support.

\subsubsection{Substance Use in Social Environment}

Three items asked whether respondent's peers, family members, and boy/girl friend use drugs (yes/no).

\subsection{Data Analysis}

The data were analyzed using descriptive statistics, the Pearson correlation, Cronbach reliability, Student's test, and multiple regression. We also examined the role of social environment variables as moderators of influences of personality on drug use. To test for moderation, separate regression analyses were specified for the combination of each moderator and each personality variable. Following guidelines on testing moderator models outlined by Baron and Kenny [34], predictor variables were entered hierarchically in the following order: (1) demographic variables including age and gender; (2) main effects for gender, personality variable tested, and proposed moderator variable; (3) two-way interactions involving Gender $\mathrm{x}$ Personality Variable, Gender x Proposed Moderator, and Personality Variable x Proposed Moderator; and (4) the three-way interaction, involving Gender $\mathrm{x}$ Personality Variable x Proposed Moderator. If the three-way interaction was significant, separate regression analyses for males and females were performed. To test interactions (or moderation effects) involving continuous variables, we centered all continuous variables, following the suggestion by Aiken and West [35]. To gain an understanding of the overall pattern of the interaction, regressions were run and regression slopes were graphically plotted at high (1 SD) and low (-1 SD) values of a moderator.

\section{RESULTS}

\subsection{Preliminary Analysis}

Because two variables: Psychoticism and Drug Use were positively skewed, all analyses were performed using logtransformed scales. 1 was added to each value before logtransformation to avoid taking logarithm of zero. Drug Use scores ranged from 0 to 3.2, mean (Std. Deviation) was 0.2 $(0.5)$. In the total sample of 3650 young people there were $547(15 \%)$ who had used drugs at least once, with boys outnumbering girls $\left(\chi^{2}=149.36 ; \mathrm{df}=1, \mathrm{p}<0.00001\right) .415$ participants $(11.3 \%$, 246 males, 169 females) indicated that they had used marijuana, 132 participants $(3.6 \%, 94$ males, 38 females) indicated that they had used opium, cocaine, hallucinogenic drugs, or stimulants, 150 participants $(4.1 \%$, 79 males, 71 females) did not indicate the kind of drugs they had used. Mean (SD) age when the respondents tried drugs for the first time was 16.0 (1.9) for males and 16.8 (2) for females. Univariate ANOVAs showed significant effects on drug use of educational setting, $\mathrm{F}(30,3467)=7.79, \mathrm{P}<$ 0.000001 , settlement, $\mathrm{F}(12,3466)=6.99, \mathrm{P}<0.000001$, and form of education (full time $v s$ correspondence), $\mathrm{F}(1,3460)$ $=34.75, \mathrm{P}<0.000001$. Higher drug use was associated with full time education and with living in some southern settlements of Novosibirsk region.

Analysis of zero-order correlations (Table 1) showed that, in agreement with the Gray's theory, BAS correlated positively with Extraversion and Psychoticism, while BIS was positively related to Neuroticism and negatively to Extraversion. Sensation seeking was positively related to BAS and negatively to BIS. Both BAS and BIS were negatively related to Subjective well-being. Setting a significance level at 0.001 , men were different from women on all but five variables. These five variables were age, Extraversion, Peer support, Boy/girl-friend drug use, and Family drug use. Men had higher drug use $(\mathrm{T}=14.9)$, BAS $(T=16.3)$, Psychoticism $(T=14.0)$, Sensation Seeking $(T=$ 7.2), Subjective well-being $(\mathrm{T}=6.9)$, Teacher support $(\mathrm{T}=$ 5.3), and Peer drug use $(T=6.9)$. Girls were higher on BIS $(\mathrm{T}=-34.0)$, Neuroticism $(\mathrm{T}=-19.9)$, Parent support $(\mathrm{T}=$ 7.2), and Boy/girl-friend support $(\mathrm{T}=-12.9)$.

\subsection{Hierarchical Multiple Regression Analysis}

Given such substantial differences, a combined analysis of males and females becomes problematic because the combined sample is not homogeneous. Homogeneity is an assumption underlying most basic statistical methods and violation of this assumption may result in unrealistic estimates, the so-called Simpson's paradox. Therefore, two regression models instead of one had to be explored: for males and females separately. Age (first block), personality variables (second block), social support variables (third block), and social environment drug use (fourth block) were entered to predict drug use. In both males and females BAS was the strongest personality predictor followed by Sensation Seeking. Peer and family drug use also appeared as significant predictors of drug use. Parent Support also entered to the equation being negatively related to drug use in females, but not in males (Table 2). Two additional regression analyses were conducted. The first one tested whether there is an effect of personality measures on the age of first use. Personality did not predict the age of first use in females. In males, Psychoticism ( $\beta=-0.16, p=0.005)$, SWB $(\beta=-0.14, p=0.016)$, and BAS $(\beta=-0.13, p=0.029)$ together explained $7 \%$ of variance of the dependent variable. The second analysis tested whether different variables predicted the use of marijuana and other drugs. Two dummy variables were constructed which matched nonusers with marijuana users and with opium, cocaine, hallucinogenic drugs, or stimulants users. Forward conditional binary logistic regression showed that $\mathrm{BAS}(\mathrm{B}=0.13$, S.E. $=0.026$, $\mathrm{p}<0.001$, odds ratio $=1.14)$, Sensation Seeking $(B=0.05$, S.E. $=0.020, p=0.010$, odds ratio $=1.05)$, peer use $(B=$ 
Table 1. Cross Correlations of All Measures ( $\mathbf{N}=\mathbf{3 6 5 0})$

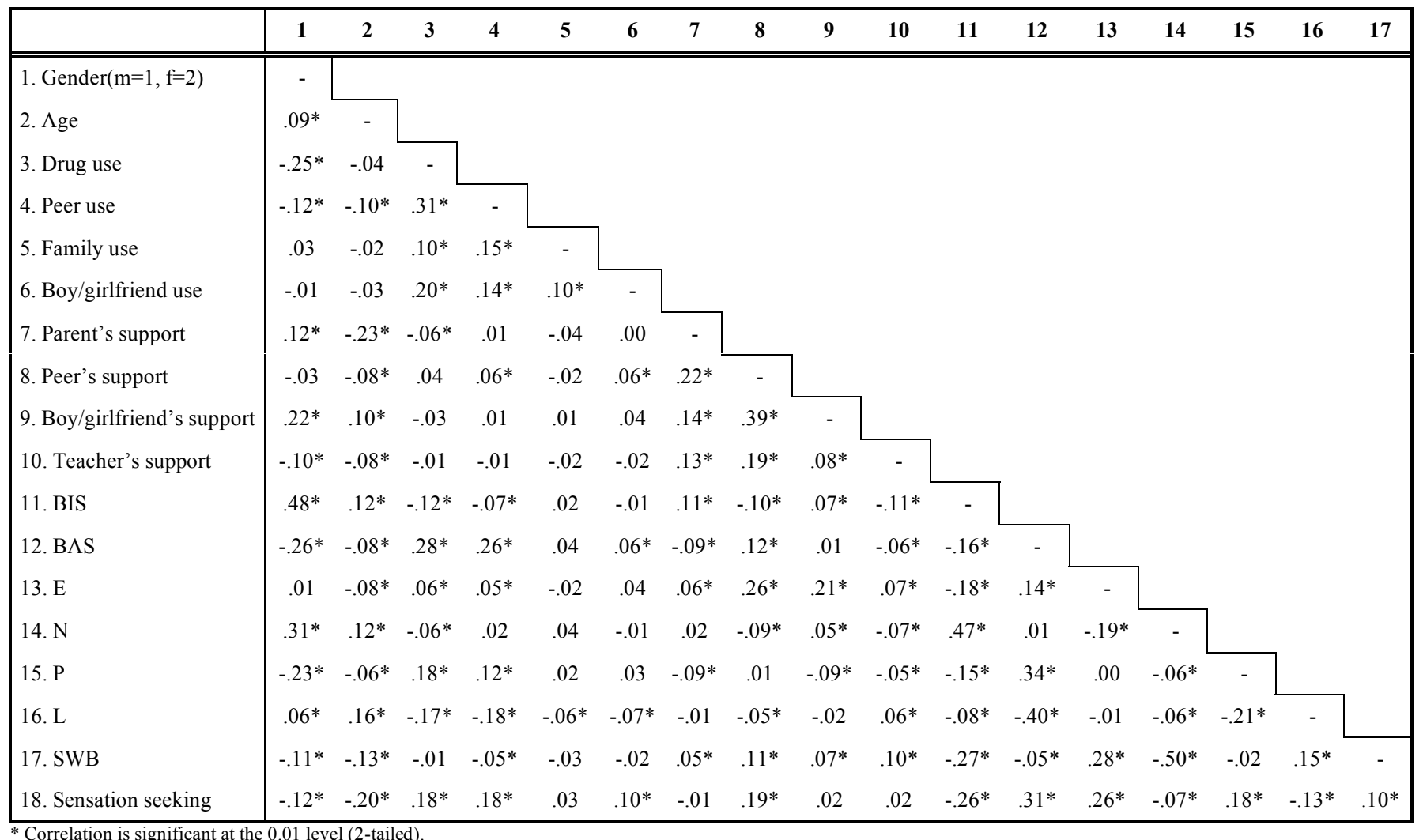

* Correlation is significant at the 0.01 level (2-tailed).

1.00 , S.E. $=0.112, \mathrm{p}<0.001$, odds ratio $=2.71)$, and girlfriend use $(\mathrm{B}=1.07, \mathrm{~S} . \mathrm{E} .=0.554, \mathrm{p}=0.050$, odds ratio $=$ 2.92) predicted marijuana use in males $(82.5 \%$ of correct classification $)$; BAS $(\mathrm{B}=0.12$, S.E. $=0.023, \mathrm{p}<0.001$, odds ratio $=1.13), \mathrm{SWB}(\mathrm{B}=-0.10, \mathrm{~S} . \mathrm{E} .=0.044, \mathrm{p}=0.028$, odds ratio $=0.91)$, parent's support $(B=-0.28$, S.E. $=0.111, p=$ 0.009 , odds ratio $=0.75)$, boyfriend use $(\mathrm{B}=1.42$, S.E. $=$ $0.428, \mathrm{p}=0.001$, odds ratio $=4.16)$, and peer use $(\mathrm{B}=0.40$, S.E. $=0.112, \mathrm{p}=0.001$, odds ratio $=1.49)$ predicted marijuana use in females ( $92.3 \%$ of correct classification); BAS $(\mathrm{B}=0.21, \mathrm{~S} . \mathrm{E} .=0.039, \mathrm{p}<0.001$, odds ratio $=1.23)$, SWB $(B=-0.14$, S.E. $=0.063, p=0.028$, odds ratio $=0.87)$, and peer use $(\mathrm{B}=0.91$, S.E. $=0.163, \mathrm{p}<0.001$, odds ratio $=$ $2.47)$ predicted other drugs use in males $(92.6 \%$ of correct classification $)$; BAS $(\mathrm{B}=0.13$, S.E. $=0.046, \mathrm{p}=0.003$, odds ratio $=1.14)$, sensation seeking $(B=0.13$, S.E. $=0.040, p=$ 0.001 , odds ratio $=1.14)$, parent's support $(B=-0.50$, S.E. $=$ $0.198, \mathrm{p}=0.014$, odds ratio $=0.61)$, and boyfriend use $(\mathrm{B}=$ 1.53 , S.E. $=0.813, \mathrm{p}=0.050$, odds ratio $=4.61)$ predicted other drugs use in females ( $98 \%$ of correct classification).

\subsection{Tests for Moderation}

Next, moderation effects between gender, personality and social environment variables were tested. Since BAS was the strongest personality predictor of substance use, only moderation effects of this personality variable were analyzed. First, the interaction between BAS and gender in prediction of substance use was tested. This interaction was significant $\left(\beta=-0.42, \mathrm{p}<0.001, \mathrm{R}^{2}\right.$ change $\left.=0.015\right)$ and it showed that the positive association between BAS and drug
Table 2. Stepwise Multiple Regression of Personality, Social Support, and Drug Use in Social Environment Variables on Drug Use Scores

\begin{tabular}{|c|c|c|c|c|}
\hline Predictor Variables & $\mathbf{R}^{2}$ & $\mathbf{R}^{2}$ Change & B & Std. Error \\
\hline \hline \multicolumn{5}{|l|}{ Males } \\
\hline BAS & 0.075 & 0.075 & $0.043^{* *}$ & 0.005 \\
\hline SS & 0.084 & 0.009 & $0.013^{*}$ & 0.004 \\
\hline PDU & 0.197 & 0.113 & $0.249^{* *}$ & 0.022 \\
\hline FDU & 0.206 & 0.009 & $0.437^{*}$ & 0.135 \\
\hline Females & & & \\
\hline BAS & 0.043 & 0.043 & $0.016^{* *}$ & 0.002 \\
\hline SS & 0.053 & 0.009 & $0.006^{* *}$ & 0.002 \\
\hline P & 0.055 & 0.003 & 0.023 & 0.011 \\
\hline Par. Supp. & 0.064 & 0.009 & $-0.041^{* *}$ & 0.011 \\
\hline FDU & 0.101 & 0.037 & $0.472^{* *}$ & 0.059 \\
\hline PDU & 0.106 & 0.005 & $0.029^{*}$ & 0.010 \\
\hline
\end{tabular}

** $\mathrm{p}<0.001 ; * \mathrm{p}<0.01$.

BAS - Behavioral Activation; SS - Sensation Seeking; P - Psychoticism; Par. Supp. Parent Support; PDU - Peer drug use; FDU - Family drug use.

use was much more pronounced in males than in females (Fig. 1). Subjective well-being significantly interacted with BAS in prediction of drug use in females $(\beta=-0.05, \mathrm{p}=$ $0.028, \mathrm{R}^{2}$ change $\left.=0.002\right)$ but not in males $(\beta=0.00$, 
$p=0.881, R^{2}$ change $\left.=0.000\right)$. The positive association of BAS with drug use was more pronounced in females with low Subjective well-being than in females with high Subjective well-being (Fig. 2). There was a significant interaction of BAS with Parent support in prediction of drug use in females $\left(\beta=-0.06, p=0.013, R^{2}\right.$ change $\left.=0.003\right)$. In males this interaction was not significant $(\beta=0.03, \mathrm{p}=$ $0.344, R^{2}$ change $=0.001$ ). As Fig. $(3)$ shows, the positive association of BAS with drug use was more pronounced in females with low Parent support than in females with high Parent support.

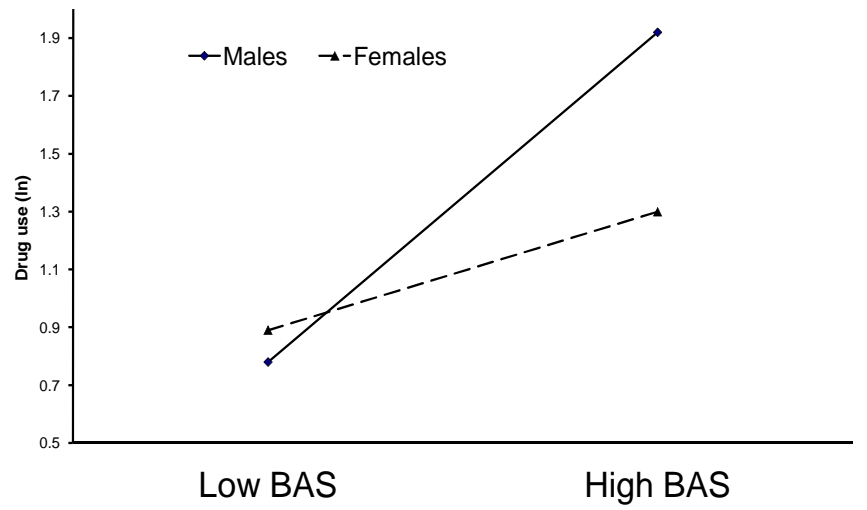

Fig. (1). A graphical plot of the relation between Behavioral Activation (BAS) and Drug Use as moderated by gender.

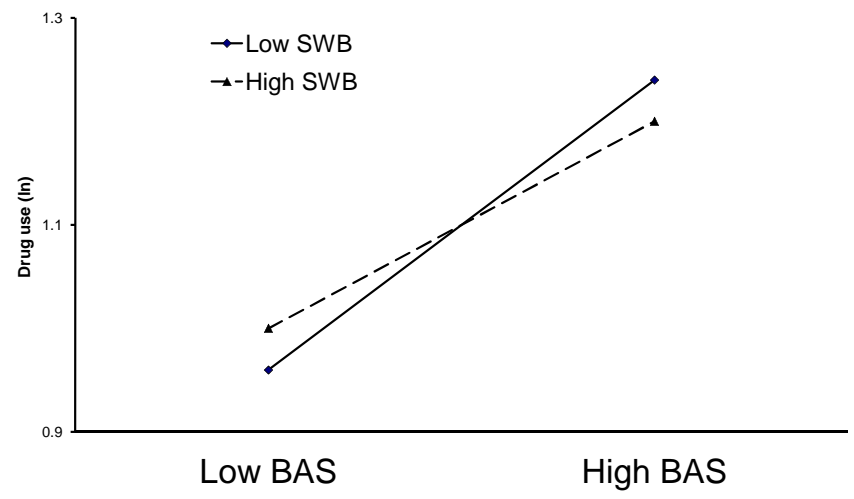

Fig. (2). A graphical plot of the relation between Behavioral Activation (BAS) and Drug Use in females as moderated by Subjective well-being (SWB). Regression lines of Drug Use on BAS are presented in the groups with below (firm line) and above (dashed line) median on SWB scale.

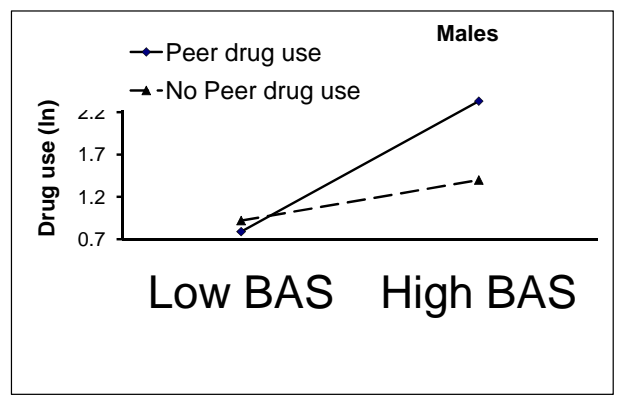

Next, moderation effects of drug use in social environment were tested. The interaction of BAS with Peer drug use was significant both in males $(\beta=0.13, \mathrm{p}<0.001$, $\mathrm{R}^{2}$ change $\left.=0.017\right)$ and in females $\left(\beta=0.09, \mathrm{p}<0.001, \mathrm{R}^{2}\right.$ change $=0.008)$. In both cases having peers using drugs substantially increased the strength of association between the BAS and drug use (Fig. 4). The interaction of BAS with Family drug use was significant only in females $(\beta=0.07, p$ $=0.002, \mathrm{R}^{2}$ change $\left.=0.004\right)$, but not in males $(\beta=0.02, \mathrm{p}=$ $0.548, \mathrm{R}^{2}$ change $\left.=0.000\right)$. In females, the association between the BAS and drug use was more pronounced when there were family members who used drugs (Fig. 5). The

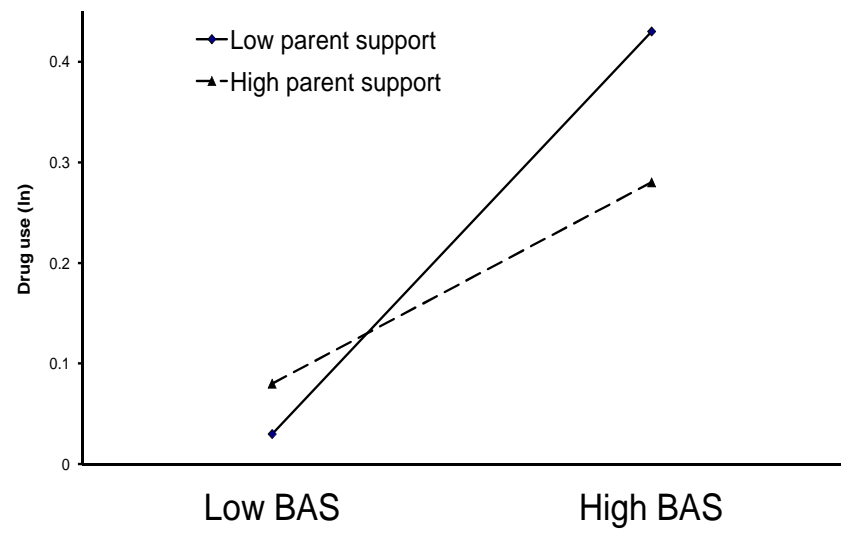

Fig. (3). A graphical plot of the relation between Behavioral Activation (BAS) and Drug Use in females as moderated by Parent support. Regression lines of Drug Use on BAS are presented in the groups with below (firm line) and above (dashed line) median on Parent support scale.

interaction between the BAS and Boy/girl-friend drug use was again significant only in females $\left(\beta=0.19, p<0.001, R^{2}\right.$ change $=0.027)$, but not in males $\left(\beta=0.03, p=0.303, R^{2}\right.$ change $=0.001)$. In females, having a boyfriend using drugs considerably increased the positive association between the BAS and drug use (Fig. 6).

\section{DISCUSSION}

The strength of this study lies in its epidemiological character and the time frame of early adulthood as an initiation period for substance use. The data show that a substantial proportion of college and university students

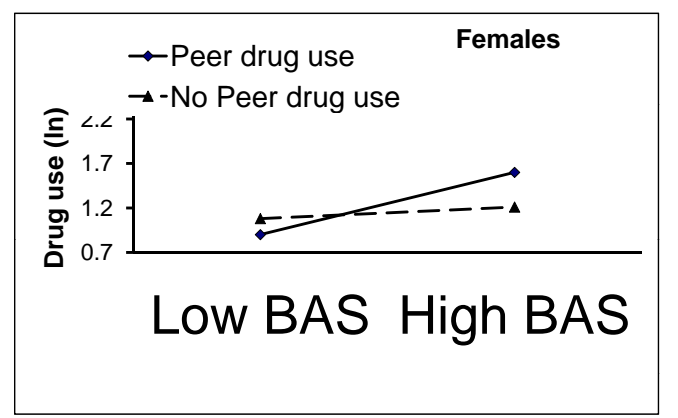

Fig. (4). A graphical plot of the relation between Behavioral Activation (BAS) and Drug Use in males (left panel) and females (right panel) as moderated by Peer drug use. Regression lines of Drug Use on BAS are presented in the groups with (firm line) and without (dashed line) Peers using drugs. 


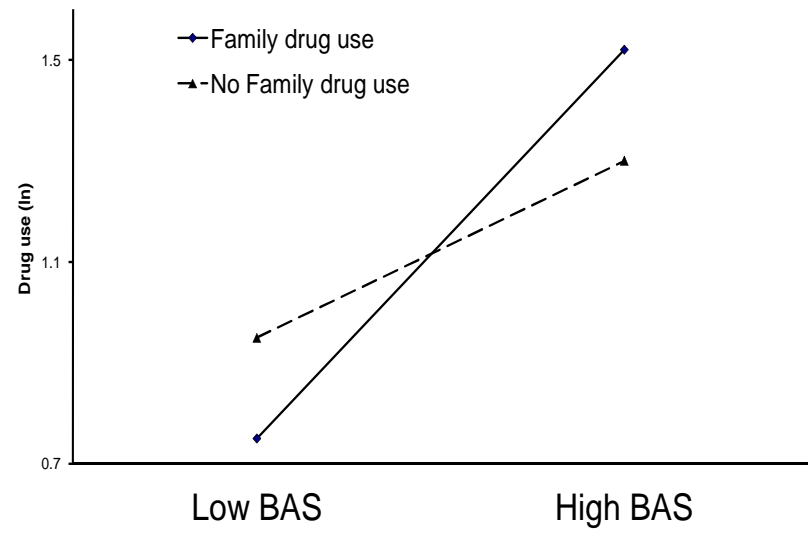

Fig. (5). A graphical plot of the relation between Behavioral Activation (BAS) and Drug Use in females as moderated by Family drug use. Regression lines of Drug Use on BAS are presented in the groups with (dashed line) and without (firm line) Family drug use.

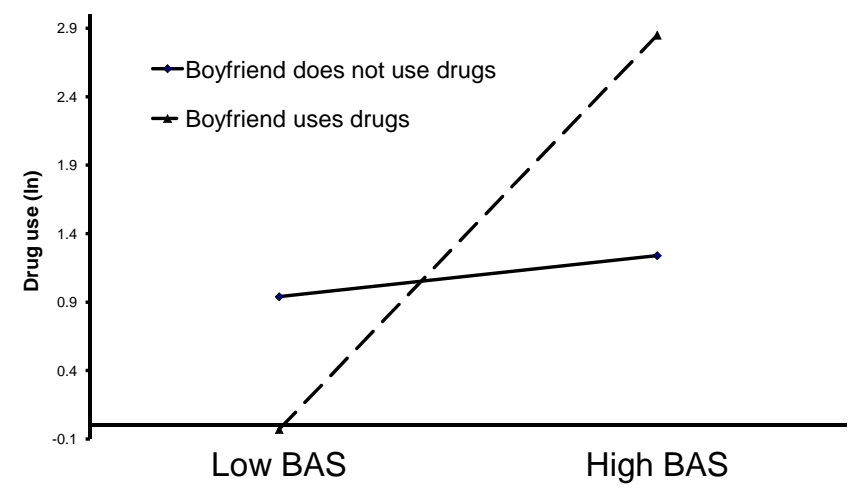

Fig. (6). A graphical plot of the relation between Behavioral Activation (BAS) and Drug Use in females as moderated by Boyfriend drug use. Regression lines of Drug Use on BAS are presented in the groups with (dashed line) and without (firm line) a boyfriend using drugs.

have experience of substance use. Detailed cross-cultural comparisons were not the aim of the present study. The precise rates vary across investigations, according to methods of assessment, definition and population studied. Substance use rates revealed in the present study are substantially higher than those reported by Steinhausen and Metzke, [31] in Swiss adolescents or by Wills et al. [18] in American adolescents, although these studies were not strictly anonymous, and the mean participant's age was lower. On the other hand, Weinberg et al. [36] summarizing data of many studies reported that "about one-half to three-quarters of older adolescents have taken an illicit drug at some time", which much more than the $15 \%$ is revealed in the present study. Substance use rates revealed in the international comparative study conducted in 1995-1997 years in Finland, Russia, Estonia, and Belgium [37] are comparable with the present study data. Specifically, $11.5 \%$ of Russian and $10 \%$ of Finnish young people indicated that they had used drugs at least once ( $15 \%$ in the present study). The substance use was higher for males than for females, in accord with a recent study in European community [38]. It should be taken into account however that the present study data were collected in 2003 and they may not reflect the current state of affairs. Indeed, in most countries the rate of drug use steadily increases over the last decade, particularly in females [39]. Nevertheless, obtained in this study estimates are close to those observed in other studies and are substantially higher than officially reported ones. For example, the Russian Ministry of Interior has reported that the number of illegal drug users could be between 3 and 4 million, while the National Scientific Centre on Addiction in Moscow estimates 2 million [40]. In a population of 150 million these estimates suggest a prevalence of 1-2\%. Estimates derived from rapid assessment studies suggest that in some Russian cities the prevalence of injecting drug users can be under $1 \%$ (for example, Belgorod and Pskov), although in the majority of locations is between $1 \%$ and $2 \%$ (for example, Kaliningrad, Kazan, Novorossiysk, Rostov and Volgograd). Estimates in Ekaterinburg, Chapayevsk, Irkutsk, Novosibirsk and Penza are as high as 3\% and 5\% [41, 42]. More recent studies conducted in provincial Russian cities report similar figures and note that they are generally lower than in the USA and some European countries [43, 44]. Mathers et al. [45] using different data sources, estimate the prevalence of injecting drug use in Russia as $1.78 \%$. It could be concluded therefore that obtained in this study prevalence estimates generally match those reported in other studies.

The present findings confirm the validity of Gray's model of personality in predicting individual differences in substance use among young people: the data clearly demonstrate that it is the dimension of BAS that is most important in determining substance use. BAS is positively related to substance use and to all variables related to substance use. These findings are consistent with Gray's theory linking BAS with risky and antisocial behaviors.

One important issue which needs to be discussed is a complex and not yet fully understood nature of the BASrelated trait. As a BAS related trait, Gray originally proposed that Impulsivity might capture the dimension running from stable introverts to neurotic extraverts [46]. However, in subsequent revisions of the Eysenck scales [47], Impulsivity shifts towards Psychoticism. Consequently, BAS reactivity was thought to be situated nearer to Psychoticism [48]. Yet later a series of works indicated that Extraversion may offer the best correspondence with functional outcomes of the BAS $[49,50]$. Numerous studies show that both Impulsivity and BAS-related trait are heterogeneous constructs. The multifaceted nature of the impulsivity construct has been widely considered with an emerging consensus that there are at least two key domains or facets of impulsivity [51, 52]. The first of these relates to reward sensitivity, the other to disinhibition, that is, an individual's tendency to persist in a previously reinforced behavior despite it no longer resulting in reward. In parallel with this development, many studies have also shown a multifaceted nature of the BAS-related trait $[53,54]$ with some facets being nearer to Extraversion and others to Psychoticism [55]. Combining these two lines of research allows to state that Extraversion-related BAS facets are associated with reward sensitivity and positive emotionality, whereas Psychoticism-related facets are associated with disinhibition. Existing literature indicates that each of these two facets has an independent contribution to the development of substance abuse and dependence [10, 52]. It has been shown that the GWPQ BAS more relates to Psychoticism, whereas the Carver and White's BAS more relates to Extraversion [55], hence utilized in this study BAS 
measure is more associated with disinhibition than with reward sensitivity and positive emotion.

It is well recognized that male gender constitutes one of the major risk factors for an array of problem behaviors. Boys are typically socialized to value independence and risktaking, characteristics that have been associated with increased risk for deviance and delinquency [56]. By contrast, definitions of femininity typically emphasize nurturance, emotionality, and passivity. Comparison of means shows that men are higher on all key variables, which are positively associated with substance use: BAS, Psychoticism, Sensation Seeking, and Peer drug use, whereas women are higher on BIS, Neuroticism and Parent support. Caution, which is linked with BIS, may prevent a person from being exposed to risky situations. Another possibility is that, on exposure to a risky situation, a person with highly active BIS would withdraw more readily.

The present study shows that association of BAS with outcome behavior is much stronger in males than in females. Besides, in females this association is more subject to moderating influences from the environment. Most of these influences act as protective factors. Delinquency tends to be viewed as inappropriate gender-role behavior for girls and is heavily proscribed. This negative feedback from adults will, no doubt, affect the girls' behavior. That may explain as to why Parent support diminishes the strength of association between BAS and drug use in females, but not in males. Although substance use in women has increased over last decades [39], it still remains much higher in males than in females, with women typically beginning to use substances later and entering treatment earlier in the course of their illnesses than do men [57]. Our data show that women are generally more sensitive to influences from the nearest environment, such as family and boyfriend, and this evidence should be taken into account while designing preventing interventions.

There are some limitations of the current study that need to be considered. First, only self-reports were used to measure family and young people functioning. Utilizing multi-informant and multi-method assessments may help to clarify the conditions that moderate the risks of the environment. Nevertheless, although the multi-informant design offers some distinct advantages, some youth behaviors (such as drug use) are typically enacted outside the purview of parents or teachers; hence, although subject to some potential biases, young people self-reports provide a key informant source for these behaviors. A second limitation is the cross-sectional nature of the data. The strategy of assessing moderator and predictor variables at a single measurement occasion limits our capacity to be clear as to the processes underlying the moderator effects. Utilizing repeated peers, family, and intrapersonal attributes in future research might help to explicate the nature of the mediating and moderating effects. Third, while the large sample size yielded considerable power to detect significant effects, it is important to note that the effect sizes were small in magnitude, implying that the large part of variance in the outcome measure is still unexplained. Nevertheless, given the difficulties involved in detecting moderators in field research, even interactions of modest magnitude are noteworthy, especially in the context of the considerable risk for health and social adjustment linked with drug use behavior.

\section{CONCLUSION}

In this study, personality and social environment predictors of drug use were investigated in a representative sample of Russian college and university students. Behavioral Activation emerged as the best personality predictor of drug use. Peer and parent support decreased the strength of association between Behavioral Activation and drug use in females, but not in males. On the other hand, drug use in near social environment significantly increased the strength of association between Behavioral Activation and drug use in males, but not in females. This evidence suggests that in predisposed to drug use youth social environment may act both as a protector and a risk factor. The former influence is stronger in females, the latter - in males.

\section{ACKNOWLEDGEMENTS}

This study was supported by a grant of the Russian Humanitarian Foundation (RHF) № 03-03-00553 a/т. During work on the paper, the author was also supported by grants of the Russian Foundation for Basic Research (RFBR) № 08-06-00016-a and № 08-06-00011-a. The author wishes to thank I.I. Kharchenko, H.R. Slobodskaya, L. G. Borisova, G. S. Solodova, and M.V. Safronova for assistance with data collection and the construction of questionnaires.

\section{REFERENCES}

[1] Ivanets NN, Anokhina IP, Strelets NV. The current status of the drug abuse problem in Russia. Zh Nevrol Psikhiatr Im S S Korsakova 1997; 9: 4-10.

[2] Francis LJ. The relationship between Eysenck's personality factors and attitude towards substance use among 13-15 year olds. Pers Individ Dif 1996; 21: 633-40.

[3] Zuckerman M. Impulsive sensation seeking and its behavioral, psycho-physiological and biochemical correlates. Neuropsychobiol 1993; 28: 30-3

[4] Gray JA. The psychophysiological basis of introversionextraversion. Behav Res Ther 1970; 18: 249-66.

[5] Pickering AD, Corr PJ, Powell JH, et al. In: Nyborg H, Ed. The Scientific study of human nature: tribute to Hans J. Eysenck at 80 . Oxford, Pergamon 1997.

[6] Pickering AD, Gray JA. In: Pervin L, John O, Eds. Handbook of Personality. $2^{\text {nd }}$ ed. New York, Guilford Press 1999.

[7] Eysenck HJ, Eysenck SBG. Manual of the eysenck personality questionnaire. London: Hodder \& Stoughton 1975.

[8] Franken IHA. Behavioral approach system (BAS) sensitivity predicts alcohol craving. Pers Individ Dif 2002; 32: 349-55.

[9] Kane TA, Loxton NJ, Staiger PK, et al. Does the tendency to act impulsively underlie binge eating and alcohol use problems? An empirical investigation. Pers Individ Dif 2004; 36: 83-94.

[10] Knyazev GG. Behavioral activation as predictor of substance use: Mediating and moderating role of attitudes and social relationships. Drug Alcohol Depend 2004; 75: 309-21.

[11] Knyazev GG, Slobodskaya HR, Kharchenko II, et al. Personality and substance use in Russian youths: The predictive and moderating Role of Behavioral activation and Gender. Pers Individ Dif 2004; 37: 827-43.

[12] Tarter RE, Vanyukov MM. Alcoholism as a developmental disorder. J Consult Clin Psychol 1994; 62: 1096-107.

[13] Scar S, McCartney K. How people make their own environments: a theory of genotype-environment effects. Child Dev 1983; 54: 42435 .

[14] Moffit TE. The neuropsychology of conduct disorder. Dev Psychopathol 1993; 5: 135-51. 
[15] Tarter RE, Moss HB, Vanyukov MM. In: Begleiter H, Kissin B, Eds. The genetics of alcoholism. New York, Oxford University Press 1995; pp. 294-326.

[16] Rutter M, Dunn, J, Plomin R. et al. Integrating nature and nurture: Implications of person-environment correlations and interactions for developmental psychopathology. Dev Psychopathol 1997; 9: 335-64.

[17] Ruchkin VV, Koposov RA, Eisemann M, Hagglof B. Alcohol use in delinquent adolescents from Northern Russia: the role of personality, parental rearing and family history of alcohol abuse. Pers Individ Dif 2002; 32: 1139-48.

[18] Wills TA, Sandy JM, Yaeger A, Shinar O. Family risk factors and adolescent substance use: moderation effects for temperament dimensions. Dev Psychol 2001; 37: 283-97.

[19] Wills TA, Windte M, Cleary SD. Temperament and noveltyseeking in adolescent substance use: Convergence of dimensions of temperament with constructs from Cloninger's theory. J Pers Soc Psychol 1998; 74: 387-406.

[20] Knyazev GG, Slobodskaya HR, Safronova MV, et al. School adjustment and health in Russian adolescents. Psychol Health Med 2002; 7: 143-55

[21] Emmons RA. Personal strivings: an approach to personality and subjective well-being. J Pers Soc Psychol 1986; 47: 1105-17.

[22] Diener E, Oishi S, Lucas RE. Personality, culture, and subjective well-being: emotional and cognitive evaluation of life. Annu Rev Psychol 2003; 54: 403-25.

[23] Wilson GD, Barrett PT, Gray JA. Human reactions to reward and punishment: a questionnaire examination of Gray's personality theory. Br J Psychol 1989; 80: 509-15.

[24] Slobodskaya HR, Safronova MV, Knyazev GG, et al. Reactions of Russian adolescents to reward and punishment: a cross-cultural study of the Gray-Wilson Personality Questionnaire. Pers Individ Dif 2001; 30: 1211-24.

[25] Knyazev GG, Slobodskaya HR, Safronova MV, et al. Personality, psychopathology and brain oscillations. Pers Individ Dif 2003; 35 : 1331-49.

[26] Knyazev GG, Slobodskaya HR, Wilson GD. Psychophysiological correlates of behavioral inhibition and activation. Pers Individ Dif 2002; 33: 647-60.

[27] Slobodskaya HR, Knyazev GG, Wilson GD. Development of a short form of the Gray-Wilson personality questionnaire: its use in measuring personality and adjustment among Russian adolescents. Pers Individ Dif 2003; 35: 1049-59.

[28] Hanin Y, Eysenck SBG, Eysenck HJ, et al. A cross-cultural study of personality: Russia and England. Pers Individ Dif 1991; 12: 26571.

[29] Hoyle HH, Stephenson MT, Palmgreen P, et al. Reliability and validity of a brief measure of sensation seeking. Pers Individ Dif 2002; 32: 401-14.

[30] Roysamb E, Harris JR, Magnus P, et al. Subjective well-being. Sex-specific effects of genetic and environmental factors. Pers Individ Dif 2002; 32: 211-23.

[31] Steinhausen HC, Metzke CW. Frequency and correlates of substance use among preadolescents and adolescents in a Swiss epidemiological study. J Child Psychol Psychiatry 1998; 39: 387-97.

[32] Borisova LG, Solodova GS, Fadeeva OP, et al. Unformal sector: economic behavior of children and adults. Novosibirsk: Novosibirsk State University Press 2001.

[33] Swickert RJ, Rosentreter CJ, Hittner JB, et al. Extraversion, social support processes, and stress. Pers Individ Dif 2002; 32: 877-91.

[34] Baron RM, Kenny DA. The moderator-mediator variable distinction in social psychological research: conceptual, strategic, and statistical considerations. J Pers Soc Psychol 1986; 51: 117382.
[35] Aiken L, West S. Multiple regression: testing and interpreting interactions. Newbury Park, London, Sage Publications, Inc. 1991.

[36] Weinberg WA, Harper CR, Brumback RA. In: Rutter M, Taylor E, Eds. Child and adolescent psychiatry: modern approaches. Oxford, Blackwell Scientific 2002; pp. 437-54.

[37] Zhuravleva IV. In: Pozdnyakova ME, Ed. Drug Addiction. Moscow, Institute of Sociology RAS 1999; pp. 34-45.

[38] van Reek J, Adrinase H. Alcohol consumption and correlates among children in the European community. Int J Addict 1994; 28 : 15-21.

[39] Kumpfer KL, Smith P, Summerhays JF. A wakeup call to the prevention field: are prevention programs for substance use effective for girls? Subst Use Misuse 2008; 43: 978-1001.

[40] Koshkina E. Prevalence of drug addiction diseases in the Russian Federation in 2000 according to official statistics. Vopr Narkol [Addiction Problems] 2001; 3: 61-71.

[41] Dehne K, Kobyshcha Y. The HIV Epidemic in Central and Eastern Europe: Update 2000. Geneva: UNAIDS 2000.

[42] Koshkina E, Koryakin S, Tsarev S. A study of the 'latent' contingent of drug addicts by the method of 'repetitive capture' in the town of Chapayevsk of Samara Region in 2000-01. Vopr Narkol [Addiction Problems] 2002; 4: 46-52.

[43] Redmond G, Spooner C. Alcohol and other drug related deaths among young people in CIS countries: proximal and distal causes and implications for policy. Int J Drug Policy 2009; 20: 38-47.

[44] Vermeiren R, Schwab-Stone M, Deboutte D, et al. Violence exposure and substance use in adolescents: findings from three countries. Pediatrics 2003; 111: 535-40.

[45] Mathers BM, Degenhardt L, Phillips B, et al. Global epidemiology of injecting drug use and HIV among people who inject drugs: a systematic review. Lancet 2008; 372: 1733-45.

[46] Gray JA. The psychophysiological basis of introversion-extraversion. Behav Res Ther 1970; 18: 249-66.

[47] Eysenck HJ, Eysenck SBG. Manual of the Eysenck Personality Questionnaire (Adult). London, Hodder \& Stoughton 1975.

[48] Pickering AD, Gray JA. The neuroscience of personality. In: Pervin L, John O, Eds. Handbook of Personality 2nd ed. New York: Guilford Press 1999.

[49] Depue RA, Collins PF. Neurobiology of the structure of personality: dopamine, facilitation of incentive motivation, and extraversion. Behav Brain Sci 1999; 22: 491-569.

[50] Smillie LD, Pickering AD, Jackson CJ. The new reinforcement sensitivity theory: implications for personality measurement. Pers Soc Psychol Rev 2006; 10: 320-35.

[51] Dickman SJ. Functional and dysfunctional impulsivity: personality and cognitive correlates. J Pers Soc Psychol 1990; 58: 95-102.

[52] Gullo MJ, Dawe S. Impulsivity and adolescent substance use: Rashly dismissed as "all-bad"? Neurosci Biobeh Rev 2008; 32: 1507-18.

[53] Carver CS, White TL. Behavioural inhibition, behavioural activation and affective responses to impending reward and punishment: The BIS/BAS scales. J Pers Soc Psychol 1994; 67: 319-33.

[54] Quilty LC, Oakman JM. The assessment of behavioural activation the relationship between impulsivity and behavioural activation. Pers Individ Diff 2004; 37: 429-42.

[55] Knyazev GG, Slobodskaya HR, Wilson GD. Comparison of construct validity of the Gray-Wilson personality questionnaire and the BIS/BAS scales. Pers Individ Diff 2004; 37: 1565-82.

[56] Hagan J, Simpson J, Gillis AR. Class in the household: a powercontrol theory of gender and delinquency. Am J Sociol 1987; 92: 788-816.

[57] Brady KT, Randall CL. Gender differences in substance use disorders. Psychiatr Clin North Am 1999; 22: 241-52. 